\title{
CONSIDERAÇÕES HISTÓRICAS SOBRE A INFLUÊNCIA DE JOHN DEWEY NO PENSAMENTO PEDAGÓGICO BRASILEIRO
}

\author{
Rodrigo Augusto de Souza \\ rodrigoaugustobr@yahoo.com.br
}

Telma Adriana Pacífico Martineli

tapmartineli@uem.br

Universidade Estadual de Maringá - UEM

\section{RESUMO:}

Este trabalho procura traçar uma trajetória histórica da influência de John Dewey (18591952), na educação brasileira. É possível estabelecer dois momentos distintos dessa influência deweyana no Brasil: o período 1930 a 1950 e, posteriormente, a década 1990. O primeiro momento foi marcado pelo embate político de introdução do ideário escolanovista no Brasil, merece destaque Anísio Teixeira (1900-1971), principal interlocutor de Dewey no Brasil. No segundo período da influência, Dewey aparece atrelado à Formação de Professores, sobretudo a partir da noção de Professor Reflexivo. A retomada, nessa segunda fase, se dá pela adoção de educadores estrangeiros, como: Nóvoa, Schön, McLaren, entre outros. Esse percurso histórico tomamos em análise no presente artigo.

Palavras-chave: Educação Brasileira. História do Pensamento Pedagógico. Educação Reflexiva. John Dewey.

\section{HISTORICAL CONSIDERATIONS ON THE INFLUENCE OF JOHN DEWEY IN BRAZILIAN PEDAGOGICAL THOUGHT}

\begin{abstract}
:
This paper attempts to trace a historical trajectory of the influence of John Dewey (18591952), in Brazilian Education. It is possible to establish two distinct moments of Dewey influence in Brazil: the period from 1930 to 1950 and later the 1990s. The first moment was marked by the political clash ideals of introduction of New School ideals in Brazil, deserves Anísio Teixeira (1900-1971), the main interlocutor of Dewey in Brazil. In the second period of influence, Dewey appears tied to teacher formation, especially from the notion of reflective teachers. The recovery in this second phase, is given by the adoption of foreign educators, as Nóvoa, Schön, McLaren, among others. This historical path we take under consideration in this article.
\end{abstract}

Keywords: Brazilian Education. History of Educational Thought. Reflective Education. John Dewey.

\section{Considerações Preliminares}

O presente trabalho tem por objetivo traçar uma trajetória histórica das idéias pedagógicas de John Dewey (1859-1952) na educação brasileira. O ponto de partida é a contextualização do pensamento deweyano no cenário do pragmatismo norte-americano, a fim de apresentar os fundamentos filosófico-educacionais que marcam o seu pensamento. 
As idéias pedagógicas de John Dewey tiveram uma importante influência sobre a educação brasileira. Nosso estudo estabelecerá dois momentos distintos que acentuam essa influência. O primeiro deles é, sem dúvida, o Movimento dos Pioneiros da Escola Nova (1932). Nesse primeiro momento é significativo o aspecto político das idéias deweyanas no Brasil, mormente por meio da atuação de Anísio Teixeira (1900-1971). Coube ao eminente educador brasileiro a tradução das principais obras de Dewey para a língua portuguesa, bem como a difusão das idéias deweyanas na educação brasileira. Anísio Teixeira foi aluno de John Dewey na Universidade de Columbia, em Nova Iorque, daí sua estreita relação com o pensamento do filósofo norte-americano.

Outro momento da influência deweyana na educação brasileira é a década de 1990. Nesse momento, John Dewey não aparece de forma tão direta e explícita como na década de 1930. Dewey é retomado a partir de conceitos fundamentais do seu pensamento, como a noção de pensamento reflexivo. Na primeira fase da influência de Dewey na educação brasileira se acentua mais o aspecto político, na tentativa de formação de uma escola pública e laica para o Brasil. Já na segunda fase, o educador norte-americano aparece atrelado à formação de professores, em especial com o conceito de Professor Reflexivo difundido por autores como Antônio Nóvoa (1999; 1992), Donald Schön (1992; 2000) e Peter McLaren (1997), entre outros. São autores estrangeiros que trazem Dewey novamente para o Brasil a partir da área de formação de professores. Portanto, nessa fase se sobressai o aspecto pedagógico em detrimento do político. É essa trajetória, no âmbito da história das idéias pedagógicas no Brasil que pretendemos realizar com o nosso trabalho.

\section{A Trajetória de um Intelectual}

Para contextualizar historicamente o pensamento de John Dewey utilizaremos duas obras fundamentais para o nosso estudo: "John Dewey: Uma Filosofia para Educadores em Sala de Aula", de Marcus Vinícius da Cunha e "Dewey: Filosofia e Experiência Democrática”, de Maria Nazaré de Camargo Pacheco Amaral. Os autores traçam o perfil de Dewey a partir de sua história familiar e também o associam à história política dos Estados Unidos.

A família Dewey chegou aos Estados Unidos em 1630, proveniente da Inglaterra e professando a fé congregacionalista. John Dewey nasceu em Burlington, a principal cidade do estado americano de Vermont, a 20 de Outubro de 1859. Filho de um proprietário de armazém teve sua infância marcada por uma escolarização desestimulante. Grande parte de sua educação foi percebida por ele como tendo sido realizada fora dos limites estreitos da escola. Contribuiu para isso o fato de que sua família cultivava o hábito de atribuir pequenas tarefas às crianças, com o intuito de despertar-lhes responsabilidade (CUNHA, 1998).

Para compreendermos o pensamento de Dewey se faz necessário uma retomada da influência religiosa por ele recebida. Os congregacionalistas defendiam a autonomia para os membros de suas igrejas, não havia ordem hierárquica para nortear as relações dos fiéis. Havia um espírito de igualdade, os ministros eram eleitos, o que poderíamos interpretar como uma forma de democracia religiosa. Instigavam a presença de Cristo nos indivíduos para que então a consequiência fosse a solidariedade. Podemos dizer que, da religião, o que influenciou Dewey não foi tanto a teologia, mas a experiência democrática e igualitária vivenciada em sua comunidade. 
Com 15 anos terminou os estudos secundários e, em seguida, ingressou na Universidade de Vermont, para estudar artes. Lá realizou estudos na área de fisiologia, tomando contato com as teses darwinistas. Nessa época, o jovem Dewey despertou para a filosofia. Em 1879, bacharelou-se em artes, exercendo em seguida o magistério em pequenas escolas da região. Sob orientação de H. Torrey, seu ex-professor em Vermont, inclinou-se para a filosofia. Em 1882, iniciou seus estudos na Universidade Johns Hopkins, de Baltimore, considerada avançada para a época nos Estados Unidos. Nesse momento, na história dos Estados Unidos, se vivia o fim da guerra civil, o desenvolvimento da indústria e do comércio. Essas características influenciaram muito o novo ensino e o pensamento de Dewey. Doutorou-se em filosofia em 1884, pela Universidade Johns Hopkins, defendendo uma tese sobre a Psicologia de Kant.

Dewey teve uma longa trajetória de vida, faleceu em 1952. Ao longo de uma existência de 92 anos produziu inúmeros trabalhos acadêmicos. Destaca-se, entre as muitas obras, "Democracia e Educação", de 1916, texto de grande importância para o pensamento pedagógico deweyano. Já para a noção de pensamento reflexivo, é de fundamental importância o livro "Como Pensamos", publicado por Dewey em 1933. Lecionou em várias universidades americanas, sobretudo em Chicago e na Universidade de Columbia, em Nova Iorque, onde permaneceu por mais de 30 anos até a sua morte. Em inúmeras viagens, Dewey proferiu conferências e tomou contato com diferentes idéias e culturas, inclusive na antiga União Soviética, onde conheceu o modelo comunista de educação. John Dewey, do ponto de vista epistemológico, tomou como referência o pragmatismo como filosofia de base para o seu pensamento. Já na perspectiva política não é tarefa fácil situá-lo, ele é crítico tanto do liberalismo quanto do capitalismo. Contudo, apesar de Dewey deixar clara sua opção pelo liberalismo, não podemos entender seu pensamento político à moda dos clássicos do pensamento liberal. Vale a pena aprofundar a perspectiva política deweyana com a leitura e análise da obra "John Dewey e a Utopia Democrática”, de Marcus Vinícius da Cunha, na qual o pesquisador toma em análise o pensamento político deweyano.

O pensamento de John Dewey está caracterizado pelo significativo avanço das ciências no século XIX. Destacamos a biologia e as teses evolucionistas de Charles Darwin (1809-1882), a sociologia de Augusto Comte (1798-1857), Max Weber (1864-1920), Émile Durkheim (1858-1917) e Karl Marx (1818-1883), enfatizando o aspecto social como problema científico e o surgimento da psicologia com Wilhelm Wundt (1832-1920), em particular da abordagem funcionalista de William James (1842-1910), surgida nas Universidades de Chicago e Columbia. A sociologia de Karl Marx não foi uma influência direta sobre Dewey, apesar disso, é possível uma aproximação entre os dois autores pela crítica ao capitalismo e a rejeição da sociedade dividida em classes. Dewey segue uma perspectiva de reforma do liberalismo e do próprio capitalismo, já Marx quer uma transformação radical da sociedade pela superação do modo de produção capitalista. Uma pesquisa mais específica poderia tratar desse assunto.

Temos assim, três fundamentos significativos para o pensamento Dewey: a biologia, a sociologia e a psicologia, a partir das abordagens já mencionadas. A filosofia deweyana alcançará uma originalidade própria, a partir da conjugação desses elementos.

\section{John Dewey e a Escola Nova no Brasil}

O pensamento filosófico de John Dewey é um dos responsáveis pelo desencadeamento na educação do movimento de renovação das idéias e das práticas pedagógicas conhecido como Escola Nova. Encontrando seu apogeu na primeira metade 
do século XX, a Escola Nova foi responsável por uma significativa mudança na chamada educação tradicional, que por sua vez era muito rigorosa, disciplinar e centrada no universo conceitual dos conhecimentos, que eram concebidos fora de qualquer finalidade utilitária. Esse tipo de educação, denominado por Dewey (1959), de "escola clássica", demonstravase insuficiente frente às inúmeras transformações históricas, sociais e econômicas ocorridas entre a segunda metade do século XIX e a primeira metade do século XX, principalmente nos Estados Unidos, país de origem de Dewey.

O pragmatismo da filosofia norte-americana influenciou muito a educação brasileira, em especial no início do século XX. No Brasil, o maior representante do pensamento deweyano é Anísio Teixeira. Ele quando foi aos Estados Unidos, tomou contato com as idéias de John Dewey e foi o responsável por introduzir no Brasil essa nova proposta de filosofia da educação e de prática pedagógica. Junto ao nome de Anísio Teixeira estão outros educadores como: Lourenço Filho, Fernando de Azevedo e Francisco Campos.

\begin{abstract}
No Brasil, com a política anti "escola nova", John Dewey, por ter sido inspirador do que pejorativamente se chamou aqui de "escola novismo", foi banido dos estudos educacionais. Passou a ser visto por muito tempo como defensor de uma educação elitista, pelos que se consideravam renovadores, e, pela direita, como um esquerdista americano que era preciso rasurar. Havia ainda os que se julgavam de esquerda e nacionalistas por recusarem qualquer influência americana e procuravam, para demonstrar seu esquerdismo, se associar ao pensamento e à pedagogia européia, desprezando tudo que vinha dos Estados Unidos. Como se do ponto de vista de identidade cultural houvesse algum avanço em baixar uma bandeira colonizadora e levantar outra igualmente colonizadora. (BARBOSA, 2002, p. 15)
\end{abstract}

Encontra-se no "Manifesto dos Pioneiros da Escola Nova", de 1932, o ideal deweyano de organizar a escola como representação da sociedade. Dewey não é a única influência do "Manifesto", porém, suas idéias são decisivas na elaboração do documento. A grande proposta de mudança na educação formal, baseada no modo aristotélico-tomista foi apresentada ao Brasil pelos "pioneiros" da Escola Nova. Esse ideal de transformação da escola brasileira não alcançará sucesso na década de 1930, sendo cerceado pela ditadura Vargas. Mais tarde, em 1959, no período pós-guerra e pós-Estado Novo, o "Manifesto" será novamente convocado. Convocação essa que não alcançará bom êxito, uma vez que o Golpe Militar de 1964 já estava a caminho, impedindo assim a educação para a democracia - ideal deweyano do qual Anísio Teixeira foi insigne defensor na educação brasileira.

Embora seguindo Dewey, estava atento às condições brasileiras e não transplantava, simplesmente, o sistema americano. Por isso, diferentemente da experiência americana, advogou em nosso país a organização de serviços centralizados de apoio ao ensino. Em outros termos: se Dewey nunca se preocupou com o sistema nacional de ensino e também nunca procurou construir instrumentos de aferição da aprendizagem e do rendimento escolar, Anísio Teixeira tinha essa preocupação e procurou, a partir das condições brasileiras, encaminhar a questão da escola pública na direção de um sistema articulado. (SAVIANI, 2000, p.173) 
Um dos empecilhos para a implantação da Escola Nova no Brasil por meio das políticas públicas foi $\mathrm{o}$ alto custo financeiro dessa proposta pedagógica. A escola idealizada por Dewey é uma escola cara, de altos custos para o Estado e suas mantenedoras. Para que a educação deweyana se desenvolva são necessários laboratórios para as ciências naturais e exatas, espaço e estrutura física adequada. Esse ideal de escola no Brasil, nos termos das políticas de educação pública foi abandonado, talvez por ser caro demais. O Estado aos poucos foi deixando o interesse por essa proposta pedagógica, fazendo-a assim, relegada à educação particular ou privada.

Os princípios da reforma escolanovista no Brasil objetivavam a rejeição do sistema dualista dos jesuítas, que havia moldado um conceito de educação aristocrático que perdurou por muito tempo. O modelo jesuítico, mais tarde sendo sucedido pelo positivista, contribuiu para uma estratificação social na educação, isto é, uma educação para pobres e ricos separados desde os primeiros anos escolares. Ela ainda buscou a rejeição do preconceito contra as atividades manuais em favor das intelectuais. $\mathrm{O}$ que se caracterizou em uma nova compreensão da atividade e da ação em educação, uma interpretação mais rica que passa pela descoberta e enriquecimento cognitivo pela atividade.

O pensamento de John Dewey está presente nos ideais de reforma educacional no Brasil na década de 1930. Na compreensão de Francisco Campos e Anísio Teixeira está a proposta deweyana de organizar a escola de acordo com a sociedade, e, em sintonia com ela. Nas palavras de Dewey, a escola organizada como "sociedade em miniatura" (DEWEY, 1959).

A influência de Dewey sobre os educadores brasileiros é notada principalmente na promoção da relação entre os programas escolares e "as atividades primárias da criança", ou seja, a tentativa de sintonizar o currículo com o desenvolvimento psicológico e cognitivo da criança. O currículo escolar se volta para o "desenvolvimento de hábitos de ações autônomas" e "hábitos de vida conjunta", o que corresponde ao ideal democrático de Dewey.

Os ideais escolanovistas estão presentes no Brasil muito antes do Manifesto dos Pioneiros da Escola Nova. Em seu livro, "Introdução ao Estudo da Escola Nova", Lourenço Filho afirma que a presença do ideário escolanovista no Brasil remonta ao final do século XIX, no Colégio Piracicabano, no interior de São Paulo, que recebia, na época, imigração de origem norte-americana, de tradição protestante. Faz-se importante notar que Anísio Teixeira não está sozinho na propagação da Escola Nova e no esforço de transformar a educação brasileira do período, a fim de adaptá-la às mudanças do mundo moderno (LOURENÇO FILHO, 1961, p.63).

Essa primeira fase da influência de Dewey no Brasil tem uma expressão máxima na década de 1930, embora seu pensamento já estivesse presente nas reformas educacionais anteriores a esse período. Merece atenção também a década de 1950, principalmente a mentalidade "desenvolvimentista" presente no contexto histórico brasileiro desse período, bem representada pelo governo de Juscelino Kubitschek. Os ideais de "modernização" e "industrialização" do Brasil se relacionam diretamente com a pedagogia de Anísio Teixeira, intérprete de John Dewey a partir da realidade brasileira. Tratava-se de um projeto "modernizador" para o Brasil vigente na época. O capitalismo industrial lançava suas bases sólidas na sociedade brasileira entre as décadas de 30 e 50 . Uma pedagogia pragmática, voltada para a técnica e a prática, ofereceria sustentação a esse ideal de nação que se pretendia instalar em nosso país. Nesse momento da história brasileira o ideário escolanovista será retomado, bem como o pensamento de Dewey. 
O novo tipo de sociedade - democrática e científica - não poderia considerar a sua perpetuação possível sem um aparelho escolar todo especial. Os velhos processos espontâneos de educação já não eram possíveis. Com todo o desenvolvimento tecnológico da sociedade, a mesma se faz, com efeito, tão complexa, artificial e dinâmica, que todo o laissez-faire se torna impossível e um mínimo de planejamento social, ajudado por um sistema de educação intencional, ou seja, escolar, de todo indispensável. (TEIXEIRA, 1968, p. 31)

Para Pitombo (1974), o criticismo é um postulado metodológico da filosofia deweyana. Segundo Dewey (1952), o projeto político liberalismo jamais se realizou. Era preciso por a perspectiva liberal à prova e desafiá-la a desenvolver uma vida social verdadeiramente democrática. Por outro lado, Dewey ficou desapontado com a experiência de comunismo da antiga União Soviética. Para ele, o comunismo tinha se transformado em um regime totalitário. A democracia seria a única forma política digna dos seres humanos. Podemos afirmar que com Anísio Teixeira a já controvertida visão política deweyana se acentua ainda mais.

\section{O Professor Reflexivo, a retomada das idéias de Dewey e suas repercussões no Brasil}

Do mesmo modo como aconteceu nas décadas de 1930 e 1950, momento de influência mais significativa do pensamento de Dewey na educação brasileira, nos anos de 1990, com o processo de redemocratização do país pós Ditadura Militar (1964-1985), e com as reformas educacionais de perspectiva neoliberal, houve uma tentativa de propagar novamente os pressupostos teóricos deweyanos, só que nesse momento, como fundamento da formação de professores. Alguns autores que deram sustentação a essa abordagem fizeram uma releitura da pedagogia de John Dewey. Houve uma tentativa de usar o pensamento deweyano para justificar essa nova matriz teórica. As idéias de Dewey apareceram como referência. A nosso ver, é uma leitura superficial realizada com o intuito de dar legitimação a essa nova visão. O Dewey crítico do liberalismo não é evocado em nenhum momento.

Devemos ver com suspeita uma filosofia educacional que, hoje, define a educação liberal com termos que são o oposto do que é verdadeiramente liberal. A educação profissional e prática não era liberal na Grécia, porque consistia na instrução de uma classe servil. [...] Uma educação verdadeiramente liberal hoje deveria negar-se a instrução profissional em qualquer dos seus níveis, do contexto social, moral e científico em que devem funcionar os ofícios e profissões sabiamente administrados. (DEWEY, 1952, p. 132)

A "Epistemologia da Prática Reflexiva" ou corrente do "Professor Reflexivo", como perspectiva teórico-metodológica para a formação de professores emergiu de um movimento mundial de reformas educacionais nos finais da década de 1980 e início da década de 1990. Esta perspectiva foi proposta por estudiosos que discutiam a formação inicial e continuada de professores em diversos países, tais como Schön (1983; 1987 e 2000) e Zeichner (1993) nos Estados Unidos, Pérez Gómez (1990 e 1992) e Marcelo García (1992 e 1999) na Espanha, Nóvoa (1992) e Alarcão (1996) em Portugal.

Esses autores trazem Jürgen Habermas (1929- ) e sua teorização sobre a razão técnico-instrumental ao cenário das discussões na educação e a partir de seus fundamentos, 
partiram do entendimento de que a formação inicial de professores nos cursos de licenciatura se constituía segundo o modelo de racionalidade técnica, no qual se privilegia nos primeiros anos os conhecimentos teóricos e, no último ano, mais especificamente, a aplicação prática destes conhecimentos. Pérez Gómez (1992, p. 99), afirmou que "[...] as derivações normativas da racionalidade técnica tipificaram uma proposta rígida na formação de professores, centrada no desenvolvimento de competências e capacidades".

Para este autor, a escola e a sala de aula são ambientes de atividades e conflitos, não podendo ficar reduzidas à racionalidade técnica, pois não dão conta de solucionar os problemas que delas emergem. É nesse sentido que a ação reflexiva, proposta por Dewey (1953; 1959), aplicada na formação inicial e continuada de professores, apresentava-se como uma possibilidade de ruptura deste modelo, sendo o ponto de partida na direção de uma racionalidade prática. Para isso, os autores propunham experiências práticas desde os primeiros anos de formação, tendo os programas como referência a investigação reflexiva na prática pedagógica.

Os proponentes da "Epistemologia prática reflexiva" reconheciam a riqueza da experiência docente que residia na prática dos professores, cujo processo de compreensão e melhoria do seu ensino deveria começar pela reflexão sobre a sua própria experiência.

Esta tendência para a formação de professores chegou ao Brasil no início, mas de forma mais expressiva em meados dos anos de 1990 e ganhou força rapidamente, ocupando espaço nas pesquisas científicas e influenciando as políticas para a formação de professores, representadas nos pareceres ${ }^{1}$ e outros documentos instituídos no âmbito legislativo no Brasil.

É nesse período que as políticas educacionais internacionais alicerçadas no modelo neoliberal, se materializaram nos documentos produzidos pelo Banco Mundial como o Relatório sobre o Desenvolvimento Mundial de 1997 e outras agências multilaterais como OIT, UNESCO, UNICEF, determinando a direção da educação dos países periféricos, entre eles o Brasil, para atender as constantes necessidades de recomposição do capital sobre o trabalho. Esta perspectiva de Educação volta-se à formação da força de trabalho necessária à sociedade regida pelo capital, fundamentada na Teoria do Capital Humano.

No Brasil esta política foi cumprida a risca e referendada nos documentos oficiais como no Plano Diretor de Reforma do Aparelho do Estado (1995) do Governo Fernando Henrique Cardoso (FHC), na Lei de Diretrizes e Bases da Educação acional (LDB, 9394/96), nos Parâmetros Curriculares Nacionais (1998); no Referencial Curricular Nacional para a Educação Infantil (RCNEI, 1998) e, nas Diretrizes para a Formação de professores da Educação Básica (2001), entre outros documentos. Embora a marca desses documentos seja a conjugação de matrizes teóricas diferenciadas, gerando certa confusão conceitual, contudo, fica fortemente marcado o viés construtivista nos documentos.

Nesse contexto político, econômico e educacional que a corrente do professor reflexivo chega ao Brasil, como perspectiva "inovadora", por meio do acesso de pesquisadores brasileiros as obras de Nóvoa em Portugal e Pérez Gómez na Espanha, especialmente. A partir de então, passou a ser objeto de estudos e pesquisas, fundamentando a legislação e desencadeando um processo de tentativa de mudanças curriculares e pedagógicas no interior dos cursos de formação.

Os autores que teorizaram e propuseram a prática reflexiva na formação de professores se reportam a John Dewey para fundamentar os pressupostos de sua teoria. Isto pode ser constatado nos escritos de Zeichner (1993), comentando sobre as origens do termo prática reflexiva nos Estados Unidos da América, quando explicita que "no princípio deste século, John Dewey fez uma importante distinção entre o ato humano que é reflexivo 
e o que é rotina. Grande parte do que Dewey disse sobre este assunto foi dirigido aos professores e continua relevante nos anos noventa" (ZEICHNER, 1993, p.17).

Nesse sentido, a formação de professores, dentro da epistemologia da prática, tem sua raiz em Dewey, derivando deste "[...] a necessidade de formar professores que venham a refletir sobre a sua prática, na expectativa de que a reflexão será um desenvolvimento do pensamento e da ação" (GARCÍA, 1992, p. 60).

Schön e McLaren $(2000 ; 1997)$ retomaram o conceito de ato de pensar e de pensamento reflexivo em Dewey como referência para as proposições da prática reflexiva docente, baseando nas obras Como Pensamos e Democracia e educação.

Em linhas gerais, Dewey (1953) considera o ato de pensar enquanto característico do ser humano e, por sua vez, o diferencial deste com os outros seres vivos. Afirma que a origem do pensamento é uma perplexidade, confusão ou dúvida e, para ocasioná-lo é preciso que algo o provoque, portanto, o "[...] problema a resolver determina o objetivo do pensamento e este objetivo orienta o processo do ato de pensar" (DEWEY, 1953, p.14). Nesse sentido, para que se desencadeie o ato de pensar é necessário que haja um fator motivador.

Dewey atribui vários sentidos à palavra pensar, do amplo para o restrito: 1) o ato de pensar ao acaso; 2) o ato de pensar limitando-se ao que ultrapassa a observação direta; 3) o ato de pensar apoiado em provas e testemunhas e, 4) o ato de pensar subentendendo-se o exame das bases e das conseqüências das crenças.

Quanto à reflexão, considera-a como processo mental no qual existem processos inferiores em toda a ação reflexiva. São eles: a) um estado de perplexidade, hesitação ou dúvida; b) atos de pesquisa ou investigação tendo o fim imediato de descobrir outros fatos que sirvam para corroborar ou destruir a convicção sugerida.

Ao buscar explicitar o conceito de pensamento reflexivo que tem por objetivo sempre chegar a uma convicção, Dewey (1953), afirma que

O pensamento reflexivo faz um ativo, prolongado e cuidadoso exame de toda a crença ou espécie hipotética de conhecimentos, exame efetuado à luz dos argumentos que apóiam a estas e das conclusões a que as mesmas chegam. (...) para firmar uma crença em uma sólida base de argumentos, é necessário um esforço consciente e voluntário (DEWEY, 1953, p. 8).

Portanto, ao considerar o pensamento reflexivo como um esforço consciente e voluntário, Dewey refere-se ao fato de que este tipo de pensamento supera a sua forma rudimentar e, para tanto, há a necessidade de um exame dos dados, procura de provas (investigação) que ocasionam um processo penoso de inquietação e conturbação.

Para Dewey (1953), tanto as formas mais rudimentares de reflexão até as mais complexas, revelam partes diversas; estas partes são apresentadas por ele divididas em cinco fases distintas:

1. $\left.{ }^{a}\right)$ uma dificuldade encontrada; $2 .^{a}$ ) a sua localização e definição; $3 .^{a}$ ) a sugestão de uma solução possível; 4. ${ }^{a}$ ) o desenvolvimento do raciocínio no sentido da sugestão; $5 .^{a}$ ) observações e experiências posteriores, conducentes a sua aceitação ou a seu afastamento, levando-nos a uma conclusão que nos fará crer, ou não, em dada coisa (DEWEY, 1953, p.78).

Outro aspecto importante é a diferença entre a reflexão propriamente dita (ou raciocínio crítico) e o ato de pensar não coordenado. Dewey $(1953$, p. 81) afirma que, 
A essência do pensamento crítico é suspender a formação de juízos; e a essência desta suspensão é provocar uma investigação para determinar a natureza do problema antes de tentar solvê-lo. Esta circunstância, mais do que qualquer outra, transforma um simples raciocínio em um raciocínio demonstrado e as conclusões sugeridas em outras tantas provas.

O ato de pensar não coordenado ocorre quando "não se pratica o esforço suficiente para se definir a dificuldade, as sugestões apresentam-se mais ou menos ao acaso" (DEWEY, 1953, p. 81).

Assim, é possível perceber que ao analisar um problema, ou seja, uma dificuldade, bem como definir a sua natureza, é fundamental eliminar qualquer tipo de julgamento prévio ou preconceito, para se evitar conclusões prematuras que levem a não resolução do problema ou a resolvê-lo de forma insatisfatória.

A terceira fase da reflexão, a sugestão de uma solução possível é entendida por Dewey (1953, p. 82) como o "verdadeiro núcleo da inferência", que preenche o espaço entre uma coisa presente e outra ausente, sendo por isso, mais ou menos especulativa e arriscada. $\mathrm{O}$ autor considera que "[...] a abundância de sugestões alternativas é fator importante para a eficiente atividade mental" (DEWEY, 1953, p. 82).

A última fase da reflexão é a verificação de uma idéia e a conseqüente formação de uma crença, ou seja, se por meio da observação e da experiência foram produzidos resultados previstos por essa idéia.

Se os resultados da experiência concordaram com os teòricamente previstos (ou racionalmente deduzidos) e caso haja razões para crer-se que só as condições em questão produziriam tais resultados, há dados suficientemente ponderosos para induzirem uma conclusão - ao menos até que fatos contrários a ela revelem a necessidade da revisão da mesma (DEWEY, 1953, p. 84).

É a partir destes pressupostos teóricos que os autores que elaboraram a "Epistemologia da prática reflexiva", estabeleceram a relação entre pensamento reflexivo e a formação docente, entendendo que existem distinções entre o ato de pensar e o pensamento reflexivo, mostrando que este último compreende uma forma mais complexa de pensar que exige um processo investigativo, no qual se valoriza os meios para se solucionar um problema.

Outro aspecto teórico que fundamentou a corrente do "professor reflexivo" esta presente no livro Democracia e Educação, no qual Dewey (1959) estabelece uma relação entre o ato de pensar e a educação, no qual afirma "[...] a importância de incentivar na escola os bons hábitos de pensar" (DEWEY, 1959, p. 167). Portanto, o autor entende que a escola pode desenvolver nos alunos uma capacidade de pensar que extrapole a forma rudimentar de pensamento, ou seja, que leve o aluno ao pensamento reflexivo e ao raciocínio crítico.

Neste sentido, Dewey (1959, p.167) dá uma importante contribuição à prática pedagógica quando afirma que

o único caminho direto para o aperfeiçoamento duradouro dos métodos de ensinar e aprender consiste em centralizá-los nas condições que estimulam, promovem e põem em prova a reflexão e o pensamento. Pensar é o método de se aprender inteligentemente, de aprender aquilo que se utiliza e recompensa o espírito. 
Deste modo, o referido autor apresenta uma forma de ensinar e aprender por meio do ensino reflexivo. A problematização motiva a ação reflexiva e o pensamento de forma a torná-los fonte de conhecimento e desenvolvimento da inteligência.

Dewey $(1953,1959)$ afirma a necessidade de educar o pensamento como forma de superação da sua forma rudimentar rumo ao pensamento reflexivo. No entanto, o desenvolvimento da prática reflexiva, só pode ocorrer a partir da necessidade de solução de um problema, que pode vir à tona por meio da experiência.

Nessa direção Zeichner (1993), autor americano que propôs a prática reflexiva na formação de professores, propõe o praticum nesta formação. Utiliza o termo praticum como sendo

todos os tipos de observação e práticas de ensino num programa de formação inicial de professores: experiências de terreno que precedem ao estágio, experiências de ligação à prática no âmbito das disciplinas ou módulos específicos e experiências educacionais dos alunos-mestres no âmbito do <ensino normal> (ZEICHNER, 1993, p. 53).

Apropriando-se das palavras de Dewey (1959, p. 169), afirmou que “[...] a questão mais importante que possa ser proposta a respeito de qualquer situação ou experiência que tenha o fim de fazer-nos aprender alguma coisa, é a qualidade dos problemas implicados neles".

Marcelo García (1992, p. 54), autor espanhol que colaborou para constituição dos pressupostos da formação reflexiva do professor, citando Sacristán (1990), afirmou que "[...] a formação de professores deve proporcionar situações que possibilitem a reflexão e a tomada de consciência das limitações sociais, culturais e ideológicas da própria profissão docente".

A literatura americana acerca da prática reflexiva no ensino indicava que a reflexão acontece antes, durante e depois da ação. Donald Schön $(1983,1987,2000)^{2}$ propôs o conceito de reflexão-na-ação, reflexão-sobre-a-ação e reflexão sobre a reflexão na ação. Schön explorou as relações dessas idéias com a prática do talento artístico e descreveu as propriedades gerais de em ensino prático reflexivo. O talento artístico profissional foi entendido por Schön (2000, p. 29) como "[...] tipos de competência que os profissionais demonstram em certas situações da prática que são únicas, incertas e conflituosas" e o ensino deste talento, na proposta do autor, ocorre por meio da reflexão-na-ação.

Alarcão (1996, p.16-17) apresentou uma síntese do pensamento de Schön acerca destes momentos de reflexão, na qual esclareceu que "[...] se reflectimos no decurso da própria acção, sem a interrompermos, embora com breves instantes de distanciamento, e reformulamos o que estamos a fazer" estamos perante um fenômeno de reflexão na acção, assim, estabelece-se um diálogo com a situação vivida. Quanto à reflexão-sobre-a-ação, Alarcão (1996, p. 17) afirmou que, esta ocorre quando "[...] reconstruímos mentalmente a acção para tentar analisá-la retrospectivamente”. Por fim, a reflexão sobre a reflexão na ação é um processo que leva o professor a progredir no seu desenvolvimento e a construir a sua forma pessoal de conhecer.

Fica evidenciado, portanto, a retomada do pensamento teórico de Dewey para situar a questão da racionalidade prática no âmbito de domínio da racionalidade técnica, na qual estiveram presentes as discussões sobre a formação reflexiva de professores nos anos de 1990. 


\section{Considerações Finais}

O percurso histórico das idéias pedagógicas de John Dewey na educação brasileira, conforme objetivado neste artigo revelou o quanto este intelectual norte-americano influenciou e ainda se faz presente no cenário educacional do nosso país.

Os dois momentos tomados como referência de análise, a década de 1930 e a década de 1990, embora com as características próprias do contexto histórico subjacente a cada um desses períodos, mostram claramente que o pensamento de Dewey ganha força no Brasil em um contexto político e econômico no qual o pensamento liberal, na sua forma mais clássica (1930) e na sua forma mais avançada, neoliberal (a partir da década de 1970, intensificando-se na década de 1990), encontra espaços para se consolidar. O pensamento Dewey foi apropriado de forma parcial em ambas as ocasiões. Ficando restrito a idéias e práticas pedagógicas que não se realizaram, ou não se consolidaram no Brasil, em um primeiro momento. Na retomada de seu pensamento, com a "epistemologia da prática reflexiva", sua obra é utilizada de maneira tendenciosa para justificar uma "nova" abordagem pedagógica. O Dewey crítico e de caráter fortemente social e progressista desaparece.

As reformas políticas, econômicas e, por consequiência, educacionais são a marca das duas fases em que as idéias de Dewey se propagam no Brasil. No entanto, é preciso ressaltar que na primeira dessas fases o alcance do seu pensamento tem um maior impacto, pela dimensão política engendrada em todo o seu processo de difusão em território nacional.

$\mathrm{Na}$ segunda fase, o impacto foi bem menor, embora estivesse atrelado a um momento de reformas educacionais na realidade brasileira, sobretudo na Educação Superior e nos cursos de Licenciatura e na Pedagogia (1987). Na década seguinte, outras novas reformas ocorreram, o que se presenciou foi um movimento intenso de críticas à corrente da epistemologia da prática reflexiva, especialmente dos marxistas. Selma Garrido Pimenta (2002), no livro "Professor Reflexivo no Brasil: Gênese e Crítica de um Conceito", nos finais dos anos de 90 e Marilda Facci (2004) no livro "Valorização ou Esvaziamento do Trabalho do Professor? Um Estudo Crítico-Comparativo do Professor Reflexivo, do Construtivismo e da Psicologia Vigotskiana", são exemplos de referência para expressar esse movimento de críticas.

Facci $(2004$, p. 62) argumenta que "os estudos sobre o professor reflexivo têm em comum a oposição a racionalidade técnica e o fato de colocarem o professor no centro do debate nos meios educacionais" e como "ativos" no processo pedagógico, adequando e transferindo assim o conceito escolanovista fundamentado em Dewey para a formação de professores. Porém, ressalta a autora, que os próprios propositores desta perspectiva de formação, como Antônio Nóvoa, reconhecem a "pobreza das práticas dos professores".

A reflexão "a respeito do nada mais do que a sua própria prática" (ARCE, 2001, p. 267), desconsiderando as condições histórico-sociais em que as se desenvolve e minimizando o valor da teoria e dos fundamentos filosóficos, políticos, sociais, históricos e de uma sólida formação didático-metodológica (FACCI, 2004), provocam um esvaziamento do conteúdo e um empobrecimento de sua prática.

Entretanto, a corrente do professor reflexivo, que afirma se fundamentar nos pressupostos teóricos de John Dewey, ainda é bastante estudada e pesquisada no tempo presente, tal como outras perspectivas que alicerçam o ideário (neo) liberal. Constata-se a permanência da produção nessa linha teórica nos bancos de teses e dissertações da CAPES. Essa produção também é visível nos anais de eventos científicos no Brasil e no exterior e nas consultas a sites de busca na internet. 
Os elementos históricos de nosso caminho teórico-metodológico nos revelaram que, indiscutivelmente Dewey é um intelectual, cujo pensamento pedagógico repercutiu de maneira marcante no contexto educacional brasileiro nas décadas de 1930 e de 1990, especialmente. Seu pensamento até hoje provoca inquietação nos meios acadêmicos e científicos, instigando o desenvolvimento de novas pesquisas.

\section{Referências}

ALARCÃO, Isabel (org.). Formação Reflexiva de Professores: Estratégias de Supervisão. Porto: Porto Editora, 1996.

AMARAL, Maria Nazaré de C. Pacheco. Dewey: Filosofia e Experiência Democrática. São Paulo: Perspectiva/Edusp, 1990.

ARCE, Alessandra. Compre o Kit Neoliberal para a Educação Infantil e Ganhe Grátis Os Dez Passos Para se Tornar um Professor Reflexivo. Educação \& Sociedade, Campinas, v. 22, n. 74, 2001.

BARBOSA, Ana Mae. John Dewey e o Ensino da Arte no Brasil. São Paulo: Cortez, 2002.

BRASIL. Referencial Curricular Nacional para a Educação Infantil. Ministério da Educação e do Desporto. Secretaria de Educação Fundamental. Brasília: MEC/SEF, 1998.

CUNHA, Marcus Vinícius. John Dewey: Uma Filosofia para Educadores em Sala de Aula. Petrópolis: Vozes, 1998.

John Dewey: A Utopia democrática. Rio de Janeiro: DP\&A, 2001.

DEWEY, John. A Filosofia em Reconstrução. São Paulo: Companhia Editora Nacional, 1958.

Como Pensamos. São Paulo: Companhia Editora Nacional, 1953.

Democracia e Educação. São Paulo: Companhia Editora Nacional, 1959.

El Hombre y Sus Problemas. Buenos Aires: Editorial Paidos, 1952.

FACCI, Marilda Gonçalves Dias. Valorização ou Esvaziamento do Trabalho do Professor? - Um Estudo Crítico-comparativo da Teoria do Professor Reflexivo, do Construtivismo e da Psicologia Vigotskiana. Campinas: Autores Associados, 2004.

GARCÍA, Carlos Marcelo. A Formação de Professores: Novas Perspectivas baseadas na Investigação sobre o Pensamento do Professor. In: NÓVOA, Antônio (coord.). Os Professores e sua Formação. Lisboa: Dom Quixote, 1992.

Formação de Professores: Para uma Mudança Educativa. Porto: Porto Editora, 1999.

GÓMEZ, Angel Pérez. O Pensamento Prático do Professor: A Formação do Professor como Profissional Reflexivo. In: NÓVOA, Antônio (coord.). Os Professores e sua Formação. Lisboa: Dom Quixote, 1992.

LOURENÇO FILHO, Manoel B. Introdução ao Estudo da Escola Nova. São Paulo: Melhoramentos, 1969.

MCLAREN, Peter. A Vida nas Escolas. Porto Alegre: Artes Médicas, 1997.

Revista HISTEDBR On-line, Campinas, n.35, p. 160-162, set.2009 - ISSN: 1676-2584 
NÓVOA, Antônio. Os Professores e sua Formação. Lisboa: Dom Quixote, 1992.

PIMENTA, Selma G.; GHEDIN, Evandro (orgs). Professor Reflexivo no Brasil: Gênese e Crítica de um Conceito. São Paulo: Cortez, 2002.

PITOMBO, Maria Isabel Moraes. Conhecimento, Valor e Educação em John Dewey. São Paulo: Pioneira, 1974.

SAVIANI, Dermeval. Sobre a Atualidade de Anísio Teixeira. In: SMOLOKA, Ana L. B. \& MENEZES, Maria C.(orgs.). Anísio Teixeira 1900 - 1971 (Provocações em

Educação). Campinas: Autores Associados; Bragança Paulista: Universidade São Francisco, 2000.

SHÖN, Donald. Formar Professores como Profissionais Reflexivos. In: NÓVOA, Antônio (coord.). Os Professores e sua Formação. Lisboa: Dom Quixote, 1992.

Educando o Profissional Reflexivo. Porto Alegre: Artmed Editora, 2000.

TEIXEIRA, Anísio. Educação é um Direito. São Paulo: Companhia Editora Nacional, 1968.

Educação Não é Privilégio. Rio de Janeiro: Editora da UFRJ, 1994.

. Educação e Mundo Moderno. Rio de Janeiro: Editora da UFRJ, 1997.

ZEICHNER, Kenneth M. A.. Formação Reflexiva de Professores: Idéias e Práticas.

Lisboa: Educa, 1993.

NOTAS:

${ }^{1}$ Com vistas a uma reforma educativa, o Parecer 009/01 do Conselho Nacional de Educação apresenta questões a serem enfrentadas na formação de professores nos campos institucional e curricular. Estas questões estavam afinadas com o discurso dos autores que defendiam a perspectiva do professor reflexivo.

${ }^{2}$ Em 1978, Schön publica "Educating the Reflective Ractitioner", nos Estados Unidos da América do Norte. Em 2000, a editora Artes Médicas publica a obra traduzida em Língua Portuguesa "Educando o Profissional Reflexivo: um novo significado para o ensino e a aprendizagem.

Artigo recebido em: 09/09/09

Aprovado para publicação em: 30/09/2009 